\title{
A Comparative Evaluation of Different Chemical Agents and Herbal Products in Disinfecting Gutta-Percha Cones: An In Vitro Study
}

\author{
Manu Bansal ${ }^{1}$ Rajinder Bansal ${ }^{1} \quad$ Nikhil Dev Wazir ${ }^{2} \quad$ Mandeep Singh Matta ${ }^{1} \quad$ Shalini Chaudhary ${ }^{1}$ \\ Priya Singla ${ }^{1}$ \\ ${ }^{1}$ Department of Conservative Dentistry and Endodontics, \\ Guru Nanak Dev Dental College and Research Institute, Sunam, \\ Punjab, India \\ 2Department of Conservative Dentistry and Endodontics,

\begin{abstract}
Address for correspondence Rajinder Bansal, MDS, Department of Conservative Dentistry and Endodontics, Guru Nanak Dev Dental College and Research Institute, Sunam, Punjab 148028, India (e-mail: drrajinderbansal@hotmail.com).
\end{abstract} Institute of Dental Sciences, Sehora, Jammu, India

Dent J Adv Stud 2020;8:36-39

\begin{abstract}
Introduction The main aim of this study was to compare and evaluate different chemical agents and herbal products in disinfecting gutta-percha (GP) cones through an in vitro study.

Materials and Methods For this study, $160 \mathrm{GP}$ cones were taken in test tubes, which were contaminated with Enterococcus faecalis inocula, prepared by dissolving it in Brain Heart Infusion (BHI) broth. The GP cones were then taken from the test tubes and dried on Whatman filter paper no. 1 and were divided into four groups according to the decontaminant used for the study-group 1 ( $5 \%$ sodium hypochlorite [ $\mathrm{NaOCl}]$ ), group 2 ( $2 \%$ chlorhexidine), group 3 (propolis), and group 4 (Aloe vera)-which were further subdivided into subgroups on the basis immersion time periods of 1 and 10 minutes. The GP cones were then again dried and taken in the test tubes containing freshly prepared BHI broth to check the turbidity.

Results It was found that $2 \%$ chlorhexidine was the most effective disinfectant

Keywords

- chemical agents

- Enterococcus faecalis

- herbal products against $E$. faecalis, $5 \% \mathrm{NaOCl}$ was the second best disinfectant followed by propolis, while Aloe vera had not shown any effect as GP disinfectant.

Conclusion Since $2 \%$ chlorhexidine showed better disinfection efficacy against E. faecalis than $5 \% \mathrm{NaOCl}$, it can be recommended for chairside disinfection of GP. Oneminute immersion of GP in $2 \%$ chlorhexidine is sufficient for elimination of $E$. faecalis.
\end{abstract}

\section{Introduction}

Gutta-percha (GP) is the most commonly used material for root canal obturation. GP is a dried coagulated extract of plants of Palaquium Blanco genus of Sapotaceae family, and was introduced to dentistry in 1847 by Edwin Truman. ${ }^{1}$ GP cones are supplied in sealed packets and they can easily get contaminated during storage, handling, and even by exposure to the clinical environment resulting in breach of aseptic chain. ${ }^{2}$ Therefore, GP must be decontaminated before being placed in root canal. GP cannot be sterilized by conventional methods like moist heat, or dry heat, because of its thermoplastic properties. Therefore, cold sterilization is recommended.

Various chemical agents have been proposed as GP disinfectants, including sodium hypochlorite $(\mathrm{NaOCl})$, glutaraldehyde, alcohol, iodine compounds, and hydrogen peroxide. ${ }^{3}$

$\mathrm{NaOCl}$ has oxidizing, hydrolyzing, and proteolytic properties. $\mathrm{NaOCl}$ is bactericidal and virucidal because of its proteolytic properties. However, these properties deteriorate with time, temperature, exposure to light, and contamination with metallic ions. ${ }^{4}$
DOI https://doi.org/ $10.1055 / \mathrm{s}-0040-1710148$ ISSN 2321-1482. 
$\mathrm{NaOCl}$ is commonly used to sterilize GP, but due to strong oxidizing effect it changes the structure of GP. ${ }^{5}$ It also causes crystal deposition on GP surface and within the canals hampering the bond of sealers with canal walls after obturation and thus leading to microleakage.

Chlorhexidine, a cationic bisbiguanide, is clinically used as antimicrobial agent. It acts by adsorbing onto the microorganism's cell wall and causing intracellular component leakage. It has antibacterial properties with broad spectrum and relatively low toxicity. ${ }^{6}$

Nowadays various herbal products are also gaining popularity to decontaminate the GP points. Various herbal products included are neem, ginger, turmeric, Aloe vera juice, and propolis.

Propolis (bee glue) is a byproduct of honeybees that is widely used in alternative medicine. ${ }^{7}$ Propolis is a resinous, yellow brown to dark brown substance that is collected by honey bees (Apis mellifera) from tree buds to seal their hives.

Aloe vera (synonym: Aloe barbadensis Miller) belongs to the Liliaceae family. ${ }^{8}$ Total leaf extracts contain anthraquinones, which have antibacterial properties. Aloe vera gel has inhibitory effects on Streptococcus pyogenes and Enterococcus faecalis because of anthraquinone. ${ }^{9}$

This present in vitro study was undertaken to compare disinfection ability of chemicals (5\% $\mathrm{NaOCl}$ and $2 \%$ chlorhexidine) and herbal products (Aleo vera and propolis) against $E$. faecalis present on the GP cones.

\section{Materials and Methods}

\section{Bacteriological Media Used in the Study}

Brain Heart Infusion broth (Hi Media) was used for cultivation of $E$. faecalis as well as to analyze the disinfection attained for GP after immersion in disinfecting agents.

\section{Procurement of Microorganism}

The microorganism, E. faecalis, used in this study was procured in freeze-dried form in an air tight glass tube from Institute of Microbial Technology, Chandigarh.

\section{Contamination of Gutta-Percha cones}

Presterilized test tubes were taken and with the help of micropipette, $5 \mathrm{~mL}$ of prepared inocula containing activated $E$. faecalis was poured in each test tube and were then incubated at $37^{\circ} \mathrm{C}$ for 30 minutes. The GP cones were taken out from sealed packets with the help of sterilized tweezer and were added into each test tube containing activated $\mathrm{E}$. faecalis (-Fig. 1). These test tubes were then incubated in an incubator at $37^{\circ} \mathrm{C}$ for 30 minutes.

\section{Disinfection of Gutta-Percha Cones}

In the study, $160 \mathrm{GP}$ cones were used. These were divided into four equal groups depending upon chemical agents or herbal products used to disinfect the GP cones.

Group $1(n=40): 5 \% \mathrm{NaOCl}$ was used to disinfect the GP cones. This group was further subdivided into two subgroups depending upon the time required to disinfect the GP cones.

Group 1a $(n=20)$ : GP cones were disinfected for 1 minute.

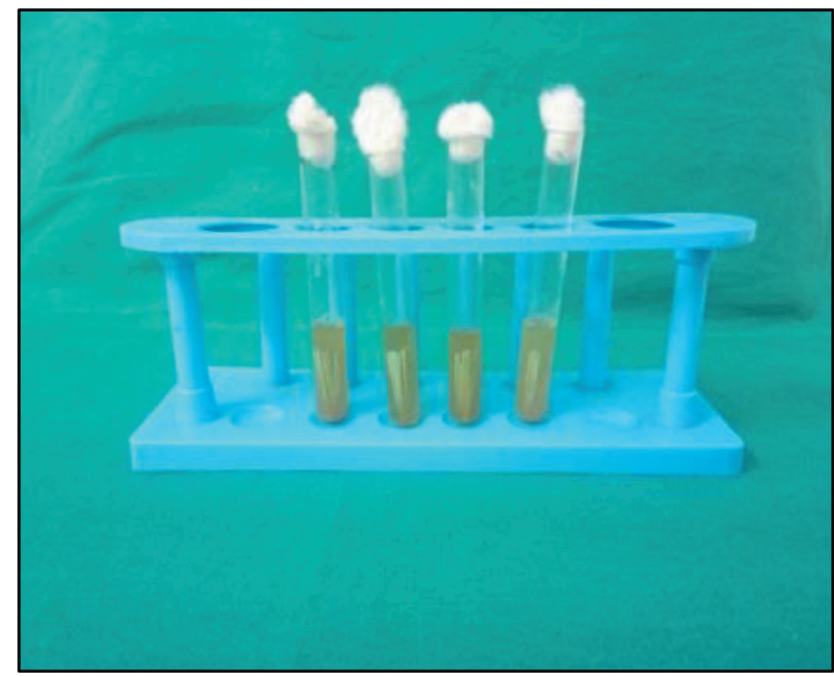

Fig. 1 Gutta-percha contamination with Enterococcus faecalis.

Four test tubes having $4 \mathrm{~mL}$ of $5 \% \mathrm{NaOCl}$ in each was taken so as to fully submerge the GP cones. Five GP cones were placed in each test tube.

Group 1b $(n=20)$ : GP cones were disinfected for 10 minutes.

Four test tubes having $4 \mathrm{~mL}$ of $5 \% \mathrm{NaOCl}$ in each was taken so as to fully submerge the GP cones. Five GP cones were placed in each test tube.

Group $2(n=40): 2 \%$ chlorhexidine was used to disinfect the GP cones. This group was further subdivided into two subgroups depending upon the time required to disinfect the GP cones.

Group 2a ( $n=20)$ : GP cones were disinfected for 1 minute.

Group 2b $(n=20)$ : GP cones were disinfected for 10 minutes.

Group $3(n=40)$ : Propolis was used to disinfect the GP. This group was further subdivided into two subgroups depending upon the time required to disinfect the GP cones.

Group 3a $(n=20)$ : GP cones were disinfected for 1 minute.

Group 3b $(n=20)$ : GP cones were disinfected for 10 minutes.

Group $4(n=40)$ : Aloe vera was used to disinfect the GP. This group was further subdivided into two subgroups depending upon the time required to disinfect the GP cones.

Group 4a $(n=20)$ : GP cones were disinfected for 1 minute.

Group $4 \mathrm{~b}(n=20)$ : GP cones were disinfected for 10 minutes.

After drying, each GP cone was individually inserted into test tubes containing Brain Heart Infusion broth and incubated at $37^{\circ} \mathrm{C}$ for 72 hours. The presence of bacterial growth was analyzed by turbidity of the medium. These test tubes were checked for turbidity after 24,48 , and 72 hours. Presence of turbidity indicated bacterial growth (-Fig. 2).

\section{Results}

Overall, $2 \%$ chlorhexidine was found to be the best disinfectant. No turbidity was observed after 24,48 , and 72 hours at 1 - and 10-minute immersion times. Also, $5 \% \mathrm{NaOCl}$ showed 


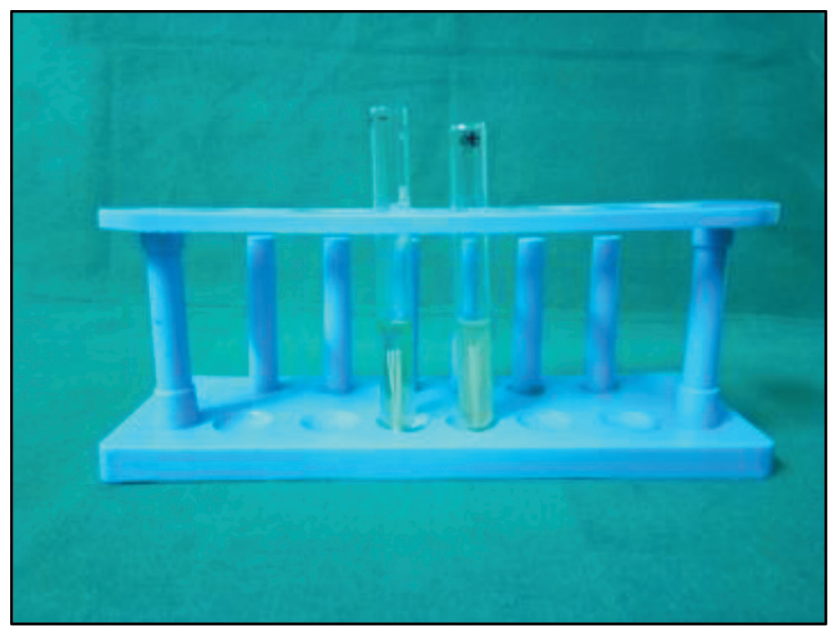

Fig. 2 Turbidity signifying bacterial growth: negative (-) tube showing absence of bacterial growth, and positive $(+)$ tube showing presence of bacterial growth.

better disinfection when immersion time was 10 minutes. Propolis showed minimum disinfection than $2 \%$ chlorhexidine and $5 \% \mathrm{NaOCl}$ irrespective of immersion time. Aloe vera did not show any antimicrobial activity. The results were obtained by using squared ranks and Wilcoxon signed rank tests, and the results were found to be statistically significant $(p<0.05 \%)(-$ Table $\mathbf{1})$.

\section{Discussion}

GP cones are widely used and accepted material to obturate the root canals. ${ }^{10} \mathrm{GP}$ was introduced to endodontics by Bowman in 1867 . The GP cones can be easily contaminated by physical contact, aerosols, gloves handling, and other sources during storage.

Nan-Shim Pang et al ${ }^{11}$ conducted a study in which they found that $19.4 \%$ of GP contaminated after exposure to clinical environment. Montgomery ${ }^{12}$ found that $8 \%$ of the commercially available cones had bacterial growth. The common contaminants of GP includes Bacillus subtilis, Staphylococcus aureus, and E. faecalis. Molander et $\mathrm{al}^{13}$ found that E. faecalis is one of the most resistant microorganisms to root canal instrumentation and irrigation procedures. Enterococci are normal human commensals, which can survive in nutrient-enriched, oxygen-depleted, ecologically complex environment of the oral cavity, gastrointestinal tract, and vaginal vault. It forms catalase negative creamy white colonies that can survive at $6^{\circ} \mathrm{C}$ for 30 minutes and can also tolerate $\mathrm{pH}$ of up to $11.1 .{ }^{14}$ It has been found that there is a high prevalence of E. faecalis in failed endodontic cases $(24-70 \%),{ }^{15}$ as it has the ability to survive harsh environmental conditions present in the root canals of endodontically treated teeth. In the present study also, E. faecalis had been used to contaminate the GP cones.

GP should be sterilized before using it to maintain the chain of asepsis in root canal treatment. The thermoplastic nature of GP does not allow sterilization by autoclaving as it may cause deformation. GP is normally sterilized by ethylene oxide. ${ }^{16}$

Many chemicals, which include thiomersal solution (0.19\%), paraformaldehyde, tincture of benzalkonium chloride, $\mathrm{NaOCl}$, hydrogen peroxide, quaternary ammonium, glutaraldehyde, and chlorhexidine, have been suggested to decontaminate GP cones. ${ }^{17}$ In our study, $2 \%$ chlorhexidine was found to be a better disinfectant than $5 \% \mathrm{NaOCl}$, propolis, and Aloe vera, irrespective of immersion time of GP, against E. faecalis. Gomes et a ${ }^{18}$ stated that $2 \%$ chlorhexidine takes less than 30 seconds to completely eliminate $E$. faecalis from contaminated GP cones. Cardoso et $\mathrm{al}^{10}$ also found that $2 \%$ chlorhexidine for 1 minute was more effective GP disinfectant than $1 \% \mathrm{NaOCl}, 2 \%$ glutaraldehyde, $6 \%$ hydrogen peroxide, and $10 \%$ polyvinyl pyrrolidone-iodine. The results of our study are similar to above investigators.

Subha et $\mathrm{a}{ }^{19}$ showed that the time required for antimicrobial property of $\mathrm{NaOCl}$ is inversely proportional to its concentration: $1 \% \mathrm{NaOCl}$ removes $E$. faecalis in 20 minutes whereas $5.25 \% \mathrm{NaOCl}$ takes less than 1 minute. This might be the reason that $5 \% \mathrm{NaOCl}$ took more time to completely disinfect the GP.

Propolis showed minimum antimicrobial effect against E. faecalis in 1-minute immersion time; however. more antimicrobial effect was observed when immersion time was 10 minutes. McHugh et al suggested that high $\mathrm{pH}(10-11)$ is necessary for growth retardation of E. faecalis. ${ }^{20}$ Ineffectiveness of propolis in our study may suggest that the $\mathrm{pH}$ of propolis was not up to the desired level, which resulted in its failure as GP disinfectant. ${ }^{21}$

Table 1 Results

\begin{tabular}{|c|c|c|c|c|}
\hline Groups & Immersion time & $\begin{array}{l}\text { Test tubes showing } \\
\text { turbidity after } 24 \mathrm{~h}\end{array}$ & $\begin{array}{l}\text { Test tubes showing } \\
\text { turbidity after } 48 \mathrm{~h}\end{array}$ & $\begin{array}{l}\text { Test tubes showing } \\
\text { turbidity after } 72 \mathrm{~h}\end{array}$ \\
\hline \multirow{2}{*}{$\begin{array}{l}\text { Sodium hypochlorite } \\
\text { (group 1) }\end{array}$} & $1 \mathrm{~min}$ & $50 \%$ & $75 \%$ & $100 \%$ \\
\hline & $10 \mathrm{~min}$ & 0 & $25 \%$ & $75 \%$ \\
\hline \multirow{2}{*}{$\begin{array}{l}\text { Chlorhexidine } \\
\text { (group 2) }\end{array}$} & $1 \mathrm{~min}$ & 0 & 0 & 0 \\
\hline & $10 \mathrm{~min}$ & 0 & 0 & 0 \\
\hline \multirow{2}{*}{$\begin{array}{l}\text { Propolis } \\
\text { (group 3) }\end{array}$} & $1 \mathrm{~min}$ & $75 \%$ & $100 \%$ & $100 \%$ \\
\hline & $10 \mathrm{~min}$ & $25 \%$ & $75 \%$ & $100 \%$ \\
\hline \multirow{2}{*}{$\begin{array}{l}\text { Aloe vera } \\
\text { (group 4) }\end{array}$} & $1 \mathrm{~min}$ & $100 \%$ & $100 \%$ & $100 \%$ \\
\hline & $10 \mathrm{~min}$ & $100 \%$ & $100 \%$ & $100 \%$ \\
\hline
\end{tabular}


Kusuma et al compared the antimicrobial activities of neem, Aloe vera, calcium hydroxide, and $2 \%$ chlorhexidine. They found that Aloe vera had minimal antimicrobial activity whereas $2 \%$ chlorhexidine showed maximum antimicrobial activity against $E$. faecalis. ${ }^{22}$

Duman et $\mathrm{al}^{23}$ suggested that poor antimicrobial activity of Aloe vera may be due to lesser acidic component and low number of monomeric anthocyanins. The results of our study show that the chemical agents, that is, $2 \%$ chlorhexidine and $5 \% \mathrm{NaOCl}$, are more effective in disinfection of GP than herbal products. Thus, $2 \%$ chlorhexidine was found to be the best among all in disinfecting the GP. Herbal products may hold promising future but more research on the use of particular concentration of these products to achieve maximum therapeutic effect is required.

\section{Conclusion}

In this study, 2\% chlorhexidine showed better disinfection efficacy against E. faecalis than $5 \% \mathrm{NaOCl}$. Thus, 2\% chlorhexidine can be recommended for chairside disinfection of GP. One-minute immersion of GP in $2 \%$ chlorhexidine is sufficient for elimination of E. faecalis.

\section{Conflict of Interest}

None declared.

\section{References}

1 Prakash R, Gopikrishna V, Kandaswamy D. Gutta-percha-An untold story. Endodontology 2005;17(2):32-36

2 Aktemur Turker S, Aslan MH, Uzunoğlu E, Özçelik B. Antimicrobial and structural effects of different irrigation solutions on gutta-percha cones. J Istanb Univ Fac Dent 2015;49(1):27-32

3 Nabeshima CK, Machado ME, Britto ML, Pallotta RC. Effectiveness of different chemical agents for disinfection of gutta-percha cones. Aust Endod J 2011;37(3):118-121

4 Estrela C, Estrela CR, Barbin EL, Spanó JC, Marchesan MA, Pécora JD. Mechanism of action of sodium hypochlorite. Braz Dent J 2002;13(2):113-117

5 Valois CRA, Silva LP, Azevedo RB. Effects of $2 \%$ chlorhexidine and $5.25 \%$ sodium hypochlorite on gutta-percha cones studied by atomic force microscopy. Int Endod J 2005;38(7):425-429

6 Marion J, Pavan K, Nakashima ML, de Morai CAH. Chlorhexidine and its applications in endodontics: a literature review. Dent Press Endod 2013;3(3):36-54

7 Zare Jahromi M, Toubayani H, Rezaei M. Propolis: a new alternative for root canal disinfection. Iran Endod J 2012;7(3):127-133

8 Tayal E, Sardana D, InduShekar KR, Saraf BG, Sheoran N. Current perspectives on use of Aloe vera in dentistry. European J Med Plants 2014;4(12):1408-1419
9 Athiban PP, Borthakur BJ, Ganesan S, Swathika B. Evaluation of antimicrobial efficacy of Aloe vera and its effectiveness in decontaminating gutta percha cones. J Conserv Dent 2012;15(3):246-248

10 Cardoso CL, Redmerski R, Bittencourt NDLRB, Kotaka CR. Effectiveness of different chemical agents in rapid decontamination of guttapercha cones. Braz J Microbiol 2000;31:72-75

11 Pang NS, Jung IY, Bae KS, Baek SH, Lee WC, Kum KY. Effects of short-term chemical disinfection of gutta-percha cones: Identification of affected microbes and alterations in surface texture and physical properties. JOE 2007;33(5):594-598

12 Montgomery S. Chemical decontamination of gutta-percha cones with polyvinylpyrrolidone-iodine. Oral Surg Oral Med Oral Pathol 1971;31:258-66

13 Molander A, Reit C, Dahlen G, Kvist T. Microbiological status of root-filled teeth with apical periodontitis. Int Endod J 1998;31:1-7

14 Filho EMM, Maia CCR, Batos ACSC, Novais TMG. In vitro antimicrobial effect of different endodontic materials and propolis on Enterococcus faecalis. R G Porto 2008;56:21-25

15 Möller B, Orstavik D. Influence of antiseptic storage solutions on physical properties of endodontic guttapercha points. Scand J Dent Res 1985;93(2):158-161

16 Chandra R, Singh S, Siddqui S, Saxena S. Evaluation of efficacy of disinfecting agents for guttapercha cones: herbal verses chemical - an in vitro study. Int J Curr Res 2017; 9(12):62740-62743

17 Shenoi PR, Morey ES, Makade C, Gunwal MK, Wanmali SS. To evaluate the antimicrobial activity of herbal extracts and their efficacy in disinfecting puttapercha cones before obturation an in vitro study. J Med Sci Clin Res 2014;2(10):2676-2684

18 Gomes BP, Vianna ME, Matsumoto CU, Rossi VdeP, Zaia AA, Ferraz CC, et al. Disinfection of gutta-percha cones with chlorhexidine and sodium hypochlorite. Oral Surg Oral Med Oral Pathol Oral Radiol Endod 2005;100:512-7

19 Subha N, Prabhakar V, Koshy M, Abhnaya K. Efficacy of peracetic acid Sodium hypochlorite, chlorhexidine, and povidone-iodine in rapid disinfection of Resilon and gutta-percha cones. JOE 2013;39(10):1261-1264

20 McHugh CP, Zhang P, Michalek S, Eleazer PD. pH required to kill Enterococcus faecalis in vitro. J Endod 2004;30(4):218-219

21 Raveendran L, Mathew M, Pathrose S, Kottoor J, Mathew J. Chair side disinfection of gutta percha points - an in vitro comparative study between a herbal alternative propolis extract with $3 \%$ sodium hypochlorite, $2 \%$ chlorhexidine and 10\% povidone iodine. Int J Bioassays 2015;4(10):4414-4417

22 Kusuma CS, Manjunath V, Gehlot PM. Comparative evaluation of neem, Aloe vera, chlorhexidine and calcium hydroxide as an intracanal medicament against Enterococcus faecalis - an in vitro study. J Clin Diagn Res 2018;12(3):21-25

23 Duman AD, Ozge M, Dayisoylu KS, Erbil N, Durgac C. Antimicrobial activity of six pomegranate (punicagranatuml.) varieties and their relation to some of their pomological and phytonutrient characteristics. Molecules 2009;14(5): 1808-1817 